\title{
XPS Study of Sol-gel Synthesized Vanadium-Titanium-Hydroquinone Oxide Bronze Films
}

\author{
Vladimiras Bondarenka ${ }^{1,2}$, Raimundas Sereika ${ }^{2^{*}}$ \\ ${ }^{1}$ Semiconductor Physics Institute, Center for Physical Sciences and Technology, \\ A. Goštauto 11, 01108 Vilnius, Lithuania \\ ${ }^{2}$ Faculty of Science and Technology, Lithuanian University of Educational Sciences, \\ Studentų 39, 08106 Vilnius, Lithuania \\ E-mail address: raimundas.sereika@leu.lt \\ *Corresponding author. Phone: +370 527900 43, fax: +370 52734857 \\ E-mail: raimundas.sereika@leu.It (R. Sereika).
}

\begin{abstract}
Keywords: X-ray photoelectron spectroscopy, sol-gel technology, vanadium oxides, hydroquinone, valence states of ions.
\end{abstract}

\begin{abstract}
Vanadium-titanium-hydroquinone oxide bronze, $\mathrm{V}_{1.67} \mathrm{Ti}_{0.33} \mathrm{O}_{5 \pm \delta}$ /HQ (HQhydroquinone), was synthesized by using the sol-gel method. Vanadium pentoxide powder, titanium dihydride, hydrogen peroxide and hydroquinone were used as the starting materials to produce bronze. The composition of the synthesized compound was compared with $\mathrm{V}_{1.67} \mathrm{Ti}_{0.33} \mathrm{O}_{5 \pm \delta} \cdot n \mathrm{H}_{2} \mathrm{O} / \mathrm{HQ}$ xerogel data. The xerogel and bronze were investigated by means of the XPS method. Analysis of the V-O region of XPS spectra showed that vanadium ions in xerogel ocurr in $\mathrm{V}^{5+}$ and $\mathrm{V}^{4+}$ states. In bronze, these ions are in a stable $\mathrm{V}^{5+}$ state. The oxygen in xerogel can be associated with $\mathrm{O}^{2-}$ ions, hydroxide grouping and water. Oxygen only exists in bronze in the form of $\mathrm{O}^{2-}$ ions and hydroxyl groups. Titanium ions in both cases are in a stable $\mathrm{Ti}^{4+}$ state.
\end{abstract}

\section{INTRODUCTION}

The mobile structure of vanadium pentoxide xerogels is composed of $\mathrm{V}_{2} \mathrm{O}_{5}$ layers linked by strongly bonded water molecules [1,2]. With the simple sol-gel method, it is possible to produce many nanocomposites by embedding various ions and radicals between the layers [3-7]. Certain physical properties of the layered nanocomposites of $\mathrm{V}_{1.67} \mathrm{Me}_{0.33} \mathrm{O}_{5 \pm \delta} \cdot n \mathrm{H}_{2} \mathrm{O}(\mathrm{Me}=\mathrm{Mo}$ or $\mathrm{Ti}$ ) xerogels intercalated with hydroquinone (chemical formula: $\mathrm{C}_{6} \mathrm{H}_{4}(\mathrm{OH})_{2}$, hereinafter referred to as HQ) and poly(vinyl alcohol) (PVA) were first described in Ref. [8]. The study demonstrated that the electrical conductivity of the xerogel produced depended on the amount of HQ used and increased along with the HQ content of the starting mixture. Proper positively charged radicals act as protons in the xerogel. X-ray photoelectron spectroscopy shows that the composites contain vanadium (V) and vanadium (IV), the $\mathrm{V} 2 p$ binding energies of which are lower than in the precursor xerogels.

Recently, interest in charge ordering investigations of vanadium oxide bronzes $\mathrm{M}_{\mathrm{x}} \mathrm{V}_{2} \mathrm{O}_{5}$ has increased. These materials are mixed-valence oxides and their properties depend on the nature of the intercalated element $\mathrm{M}[9,10]$. Bronzes are usually prepared by means of solid-state chemical reactions that demand high temperatures and precise temperature regimes for producing thermodynamically stable phases [9]. A wide range of vanadium pentoxide-based bronzes can be synthesized using hydrothermal methods, which require special equipment $[11,12]$. The thin films of the bronzes can be produced by using thermal evaporation, which also demands special equipment $[13,14]$. All the methods described above demand the application of high-temperature and special equipment. However, there is a simpler method for the production of thin films: sol-gel synthesis. During this process, vanadium oxide-based compounds are produced from aqueous precursors [15]. The sol-gel process for the production of vanadium oxide bronzes can be described as follows: $\mathrm{V}_{2} \mathrm{O}_{5}$ gel is produced, the required element is intercalated to the structure of the gel, and 
the resulting hydrate is heated up to a temperature that ensures the removal of all water (absorbed, zeolyte type and chemically bonded) from the compound. Layered nanocomposites with conductive polymerized layers were prepared as a result of the intercalation of various molecular compounds into interlayer spaces of vanadium pentoxide gels [16-19]. In those compounds, the conductive layers were separated by water molecules. If the water molecules are somehow removed from the gel, the process will result in a molecular bronze. Sol-gel synthesis and the XPS study of vanadiumhydroquinone oxide bronze $\mathrm{V}_{2} \mathrm{O}_{5 \pm \delta} \cdot n \mathrm{H}_{2} \mathrm{O}$ /HQ are described in [20].

The present study aims to produce vanadium-titanium-hydroquinone oxide bronze by using sol-gel technology with hydroquinone maintenance twice smaller than described in [20], and to define the valence states of vanadium and titanium ions by using the XPS method.

\section{EXPERIMENTAL}

Vanadium pentoxide powder $\left(\mathrm{V}_{2} \mathrm{O}_{5}, 99.9 \%\right.$ purity, Sigma-Aldrich), titanium dihydride $\left(\mathrm{TiH}_{2}\right.$, 99.7\% purity, Atlantic Equipment Engineers), hydrogen peroxide $\left(\mathrm{H}_{2} \mathrm{O}_{2}, 99 \%\right.$ purity, Standard) and hydroquinone $\left(\mathrm{C}_{6} \mathrm{H}_{4}(\mathrm{OH})_{2}, 99 \%\right.$ purity, Sigma-Aldrich) were used as the starting materials for producing bronze. $\mathrm{V}_{2} \mathrm{O}_{5}$ and titanium dihydride were prepared in molar ratio 1.67:0.33 and dissolved in hydrogen peroxide at a temperature of $273 \mathrm{~K}$. The solution was then heated to 333-334 $\mathrm{K}$ and exposed at this temperature until the peroxide complexes of vanadium and titanium fully decomposed and resulted in $\mathrm{V} \mathrm{V}_{1.67} \mathrm{Ti}_{0.33} \mathrm{O}_{5 \pm \delta} \cdot n \mathrm{H}_{2} \mathrm{O}$ gel. An aqueous solution of hydroquinone was mixed with the resulting gel in molar ratio $0.17: 1.00$. It must be noted that in [20] this ratio equaled 0.33:1.00. The synthesized $\mathrm{V}_{1.67} \mathrm{Ti}_{0.33} \mathrm{O}_{5 \pm \delta} \cdot n \mathrm{H}_{2} \mathrm{O} / \mathrm{HQ}$ gels were applied to a $\mathrm{Ni}$ pad and air-dried. The xerogels formed were about $0.01 \mathrm{~mm}$ thick. The xerogels were then heated up to $580 \mathrm{~K}$ in air for $1 \mathrm{~h}$ in order to remove water and produce the bronze.

XSAM 800 (Kratos Analytical, UK) was used to record X-ray photoelectron spectra. A nonmonochromatized $\mathrm{Mg} \mathrm{K} \alpha(1,253.6 \mathrm{eV})$ radiation source excited the photoelectrons at $15 \mathrm{kV}, 300$ W. During the spectrum analysis, the working pressure fell below $10^{-7} \mathrm{~Pa}$ in the analysis chamber. The analyzer used an energy resolution of $\Delta \mathrm{E} / \mathrm{E}=0.08 \%$ in steady retarding mode. Using the KRATOS DS800 data system, the photoemission data was collected and processed. Multiple photoelectron spectra were separated into several peaks by setting peak positions: binding energy (BE), area (A), width (FWHM) and Gaussian/Lorentzian (G/L) ratio, after the $\mathrm{Mg} \mathrm{Ka}$ source satellites and background deduction. The accuracy of the relative intensities and $\mathrm{BE}$ of the measured lines were about $10 \%$ and $0.1 \mathrm{eV}$ respectively. The random $\mathrm{C} 1 \mathrm{~s}$ line, the $\mathrm{BE}$ of which should have been equal to $284.6 \mathrm{eV}$, was used for the correction of the charging effects. After the removal of satellite peaks and Shirley background subtraction, a non-linear least squares curve fitting routine with a Gaussian/Lorentzian product function was used for the analysis of the XPS spectra.

\section{RESULTS AND DISCUSSION}

Figure 1 shows a typical XPS spectrum of a titanium region for $\mathrm{V}_{1.67} \mathrm{Ti}_{0.33} \mathrm{O}_{5 \pm \delta} \cdot n \mathrm{H}_{2} \mathrm{O} / \mathrm{HQ}$ xerogel. The XPS spectrum for bronze is very similar. Titanium peaks consist of spectral doublet $\mathrm{Ti}$ $2 p_{3 / 2}$ and $\mathrm{Ti} 2 p_{1 / 2}$ with binding energies of about $458 \mathrm{eV}$ and $464 \mathrm{eV}$ respectively. The values of BE are typical of titanium dioxide $[21,22]$. Similar stable states of $\mathrm{Ti}^{4+}$ ions were observed in vanadium-titanium hydrates $[23,24]$. The fitting parameters of titanium spectra are listed in Table 1.

The vanadium-oxygen region in the XPS spectra of the xerogel and bronze investigated are compared in Fig. 2. The fitting components are presented in Table 2. The $\mathrm{V} 2 p_{3 / 2}$ peak of the $\mathrm{V}_{1.67} \mathrm{Ti}_{0.33} \mathrm{O}_{5 \pm \delta} \cdot n \mathrm{H}_{2} \mathrm{O} / \mathrm{HQ}$ xerogel spectrum (Fig. 2a) consists of two components with a BE of $517 \mathrm{eV}$ and $\sim 516 \mathrm{eV}$ (see Table 2), which correspond to $\mathrm{V}^{5+}$ and $\mathrm{V}^{4+}$ ions respectively [22, 25-27]. The $\mathrm{O} 1 s$ peak of the same xerogel consists of three components with a BE of $\sim 530 \mathrm{eV}, \sim 531 \mathrm{eV}$ and $\sim 533 \mathrm{eV}$, which correspond to $\mathrm{O}^{2-}$ ions connected with vanadium and titanium ions, hydroxyl groups $(\mathrm{OH})^{-}$and oxygen in water molecules, respectively [22, 28-30]. Similar XPS spectra were 
observed in various hydrated compounds based on vanadium pentoxide [4, 20, 31, 32]. After thermal treatment at $580 \mathrm{~K}$, as described in the experimental section of this study, the XPS spectrum of the vanadium-oxygen region changes radically. The $\mathrm{V} 2 p_{3 / 2}$ and $\mathrm{V} 2 p_{1 / 2}$ peaks remain with only one component (Fig. $2 \mathrm{~b}$ and Table 2). The BE of the $\mathrm{V} 2 p_{3 / 2}$ peak is about $517 \mathrm{eV}$, which corresponds to $\mathrm{V}^{5+}$ ions [22, 25-27]. The $\mathrm{O} 1$ s peak consists of two components with a $\mathrm{BE}$ of $\sim 530$ $\mathrm{eV}$ and $\sim 531 \mathrm{eV}$ (Fig. $2 \mathrm{~b}$ and Table 2), which correspond to $\mathrm{O}^{2-}$ ions and oxygen in the $(\mathrm{OH})^{-}$ group [22, 28-30]. However, in this case there is no component of the $\mathrm{O} 1 \mathrm{~s}$ peak that corresponds to the water molecules. This fact is no surprise as it is known that after the thermal treatment of vanadium hydrates at $580 \mathrm{~K}$, the chemically bonded water completely leaves the samples [3, 20, 3133]. The presence of an $(\mathrm{OH})^{-}$component in the $\mathrm{O} 1 s$ peak for xerogel and bronze (Fig. 2) partially indicates that we have truly introduced hydroquinone in the vanadium-titanium oxide xerogel matrix as, for example, this component cannot be observed in pure temperature-treated $\mathrm{V}_{2} \mathrm{O}_{5}[33$ ]

The carbon region of XPS spectra for $\mathrm{V}_{1.67} \mathrm{Ti}_{0.33} \mathrm{O}_{5 \pm \delta} \cdot n \mathrm{H}_{2} \mathrm{O} / \mathrm{HQ}$ xerogel and for bronze is similar (Fig. 3). The $\mathrm{C} 1 s$ peak consists of three components with a BE of $284.6 \mathrm{eV}(\mathrm{C}-\mathrm{C}$ bonding, the value of this energy was used for the correction of the charging effects), $284.0 \mathrm{eV}(\mathrm{C}-\mathrm{H}$ bonding [34]) and $287.6 \mathrm{eV}(\mathrm{C}-\mathrm{O}$ bonding [35]). These results and the above-mentioned results of the $\mathrm{O} 1 \mathrm{~s}$ peak analysis confirm that vanadium-titanium-hydroquinone oxide bronze was synthesized. This is also confirmed by the fact that $\mathrm{O}-\mathrm{H}, \mathrm{C}-\mathrm{O}$ and $\mathrm{C}-\mathrm{H}$ bonding exists in the hydroquinone $\mathrm{C}_{6} \mathrm{H}_{4}(\mathrm{OH})_{2}$ molecule. The final formula of the bronze produced can be identified as $\mathrm{V}_{1.67} \mathrm{Ti}_{0.33} \mathrm{O}_{5 \pm \delta} / \mathrm{HQ}$.

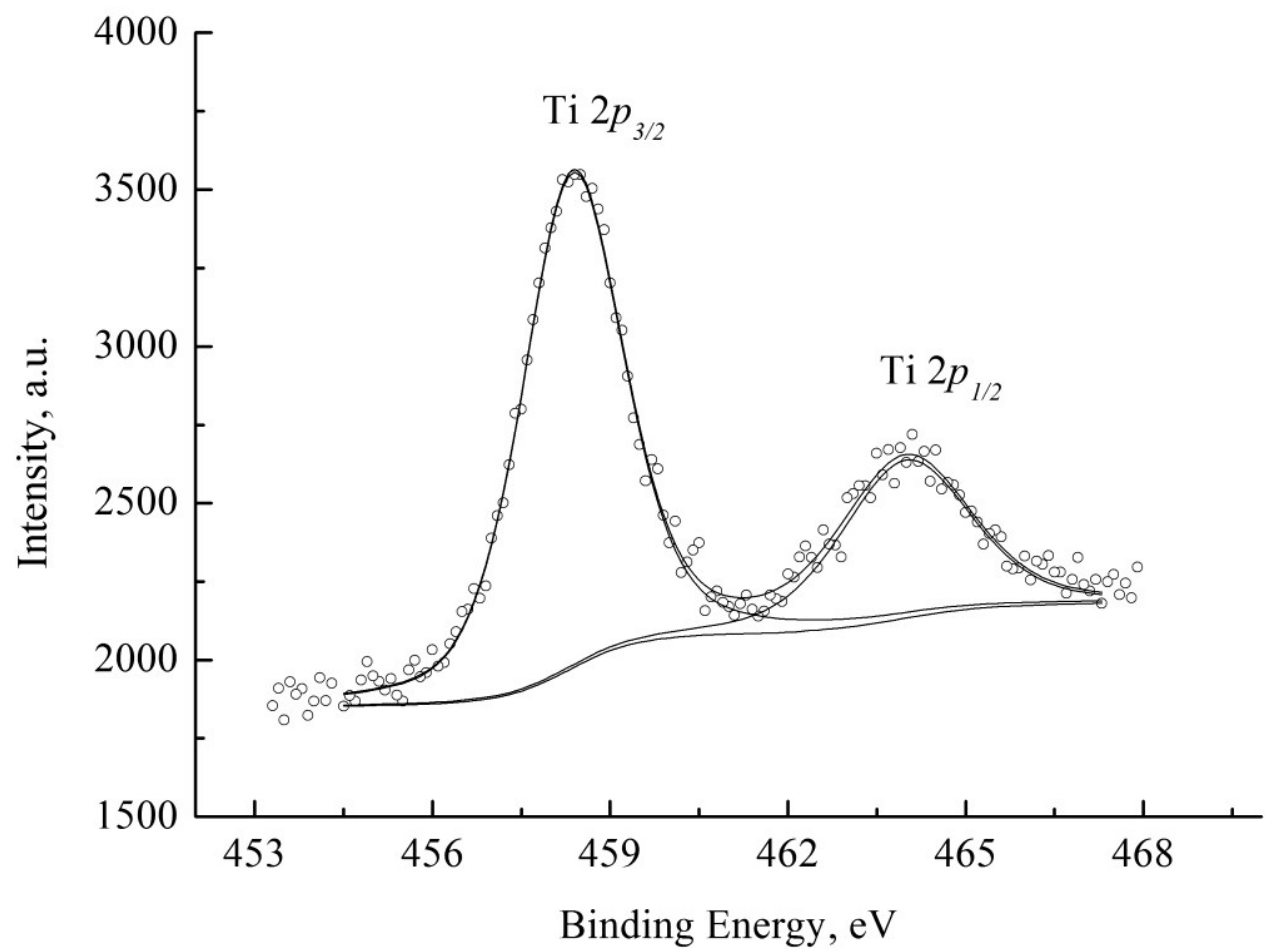

Fig. 1. Titanium region XPS spectrum for $\mathrm{V}_{1.67} \mathrm{Ti}_{0.33} \mathrm{O}_{5 \pm \delta} \cdot n \mathrm{H}_{2} \mathrm{O} / \mathrm{HQ}$ xerogel. 


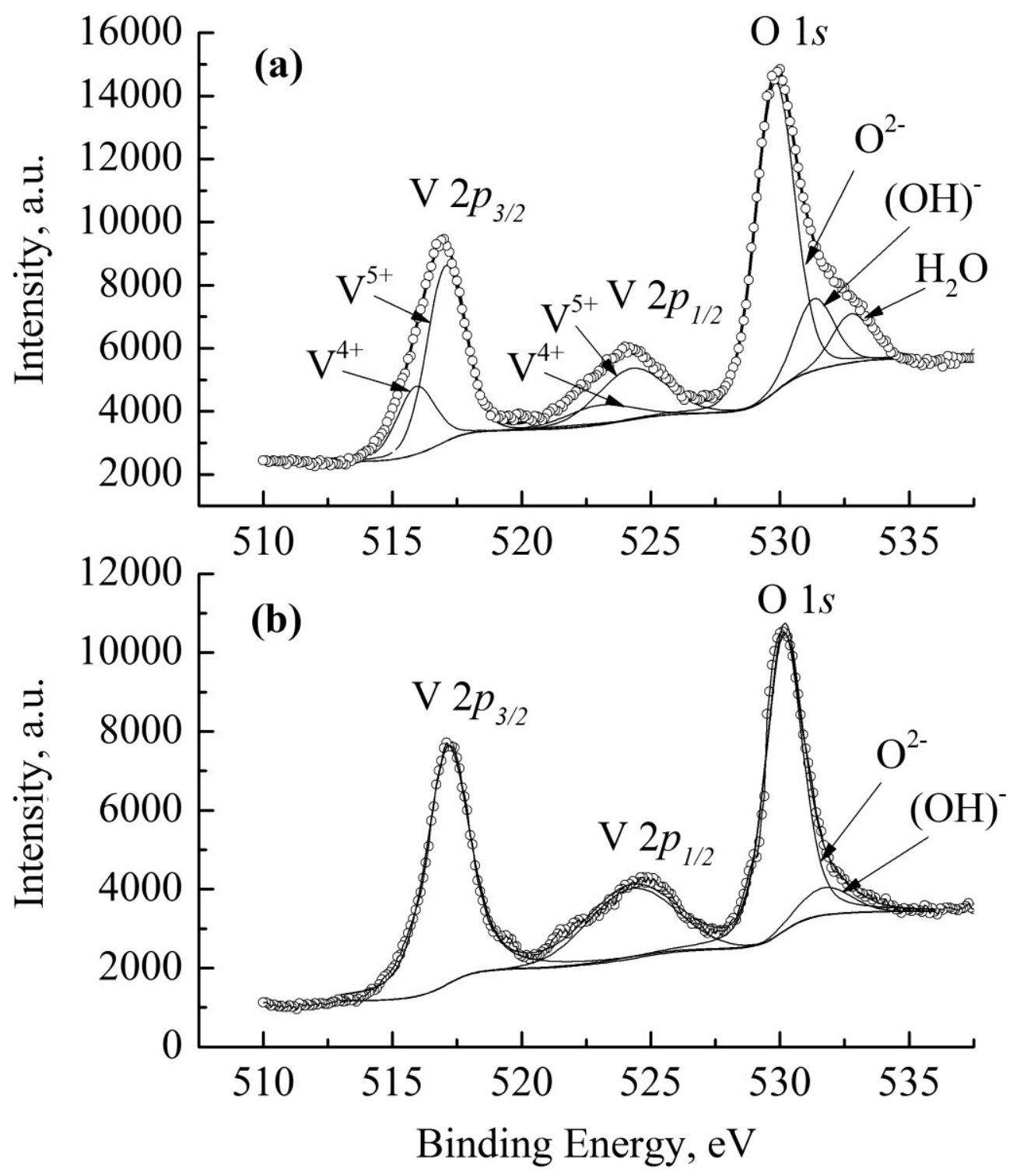

Fig. 2. V $2 p$-O $1 s$ spectra for $\mathrm{V}_{1.67} \mathrm{Ti}_{0.33} \mathrm{O}_{5 \pm \delta} \cdot n \mathrm{H}_{2} \mathrm{O} / \mathrm{HQ}$ xerogel (a) and bronze (b) samples. 


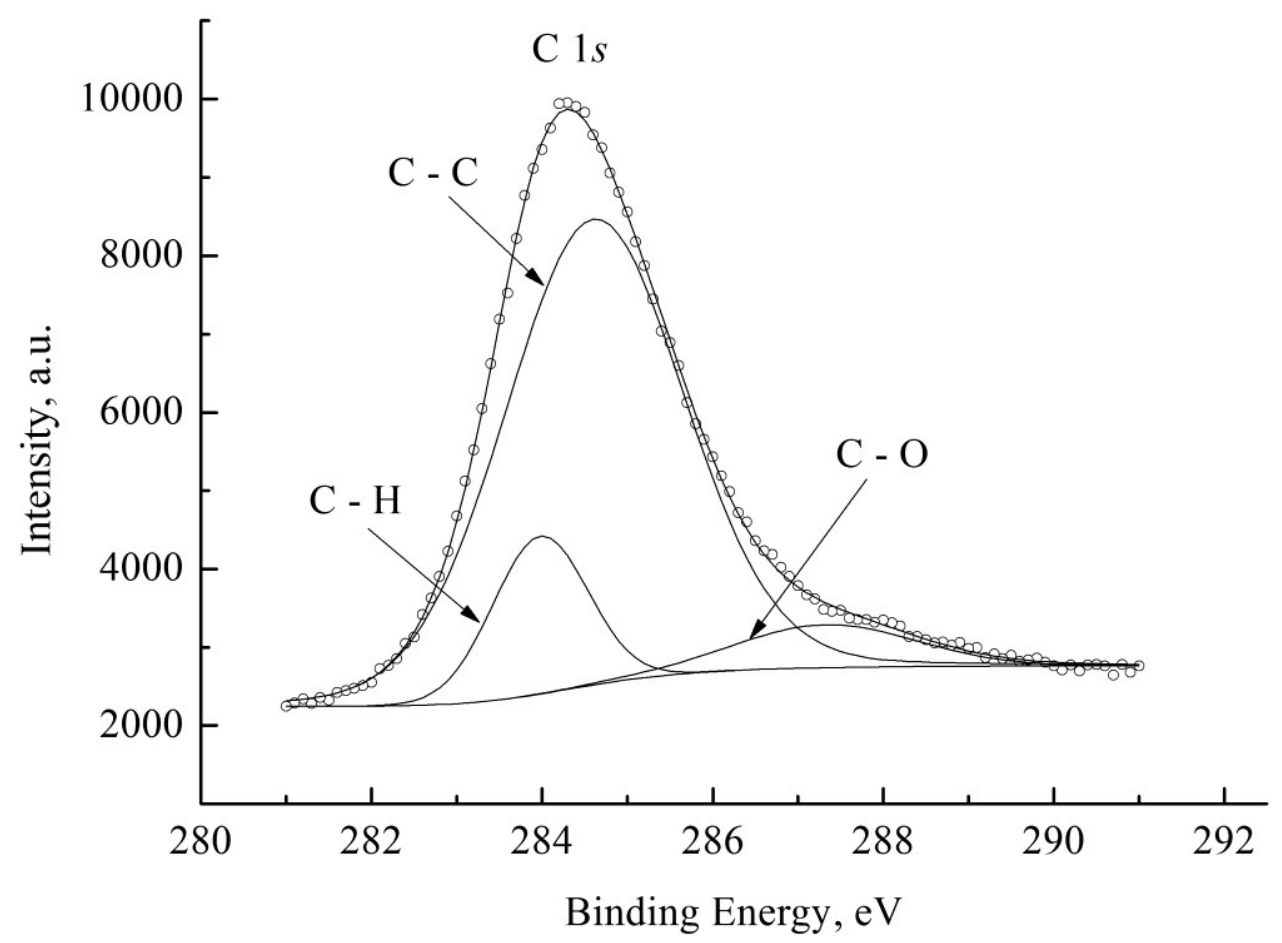

Fig. 3. Carbon region XPS spectrum for $\mathrm{V}_{1.67} \mathrm{Ti}_{0.33} \mathrm{O}_{5 \pm \delta} \cdot n \mathrm{H}_{2} \mathrm{O} / \mathrm{HQ}$ xerogel.

Table 1. Comparison of titanium region fitting parameters for $\mathrm{V}_{1.67} \mathrm{Ti}_{0.33} \mathrm{O}_{5 \pm \delta} \cdot n \mathrm{H}_{2} \mathrm{O} / \mathrm{HQ}$ xerogel and bronze.

\begin{tabular}{|c|c|c|c|c|}
\hline \multicolumn{5}{|c|}{ Xerogel } \\
\hline Peak & Binding energy, eV & FMWH, eV & RA $^{1}, \%$ & G/L ${ }^{2}, \%$ \\
\hline Ti $2 p_{3 / 2}$ & 458.33 & 1.83 & 68.4 & 31 \\
\hline Ti $2 p_{1 / 2}$ & 464.02 & 2.35 & 31.6 & 31 \\
\hline \multicolumn{5}{|c|}{ Bronze } \\
\hline Ti $2 p_{3 / 2}$ & 458.29 & 1.98 & 65.95 & 30 \\
\hline Ti $2 p_{1 / 2}$ & 463.99 & 2.87 & 34.05 & 30 \\
\hline
\end{tabular}

${ }^{1} \mathrm{RA}$ : relative area of peak.

${ }^{2} \mathrm{G} / \mathrm{L}$ : Gaussian/Lorentzian ratio.

Table 2. Comparison of vanadium-oxygen region fitting parameters for $\mathrm{V}_{1.67} \mathrm{Ti}_{0.33} \mathrm{O}_{5 \pm \delta} \cdot n \mathrm{H}_{2} \mathrm{O} / \mathrm{HQ}$ xerogel and bronze.

\begin{tabular}{|c|c|c|c|c|}
\hline \multicolumn{5}{|c|}{ Xerogel } \\
\hline Peak & Binding energy, eV & FMWH, eV & $\mathrm{RA}^{1}, \%$ & $\mathrm{G} / \mathrm{L}^{2}, \%$ \\
\hline $\mathrm{V} 2 \mathrm{p}_{3 / 2}\left(\mathrm{~V}^{5+}\right)$ & 517.21 & 1.75 & 21 & 17 \\
\hline $\mathrm{V} 2 \mathrm{p}_{3 / 2}\left(\mathrm{~V}^{4+}\right)$ & 515.82 & 1.75 & 11 & 17 \\
\hline $\mathrm{O} 1 \mathrm{~s}\left(\mathrm{O}^{2-}\right)$ & 529.81 & 1.76 & 47 & 17 \\
\hline $\mathrm{O}_{1 \mathrm{~s}}(\mathrm{OH})^{-}$ & 531.42 & 1.76 & 13 & 17 \\
\hline $\mathrm{O} 1 \mathrm{~s}\left(\mathrm{H}_{2} \mathrm{O}\right)$ & 532.96 & 1.76 & 8 & 17 \\
\hline \multicolumn{5}{|c|}{ Bronze } \\
\hline $\mathrm{V} 2 \mathrm{p}_{3 / 2}\left(\mathrm{~V}^{5+}\right)$ & 517.15 & 2.28 & 41 & 21 \\
\hline $\mathrm{O} 1 \mathrm{~s}\left(\mathrm{O}^{2-}\right)$ & 530.13 & 1.98 & 48 & 21 \\
\hline $\mathrm{O} 1 \mathrm{~s}(\mathrm{OH})^{-}$ & 531.49 & 1.98 & 11 & 21 \\
\hline
\end{tabular}

${ }^{1}$ RA: relative area of peak.

${ }^{2} \mathrm{G} / \mathrm{L}$ : Gaussian/Lorentzian ratio. 


\section{CONCLUSIONS}

$\mathrm{V}_{1.67} \mathrm{Ti}_{0.33} \mathrm{O}_{5 \pm \delta} \cdot n \mathrm{H}_{2} \mathrm{O} / \mathrm{HQ}$ xerogel and $\mathrm{V}_{1.67} \mathrm{Ti}_{0.33} \mathrm{O}_{5 \pm \delta} / \mathrm{HQ}$ bronze samples were produced by using sol-gel technology. The X-ray photoelectron spectra measured demonstrated that the valence of vanadium ions for the xerogel studied has two states: $\mathrm{V}^{5+}$ and $\mathrm{V}^{4+}$. In the bronze, vanadium ions exist only in highest degree of oxidation. Titanium ions in both cases are in the stable $\mathrm{Ti}^{4+}$ state. The $\mathrm{O} 1 \mathrm{~s}$ peak of the xerogel consists of three components that can be explained by $\mathrm{O}^{2-}$ ions bonded to vanadium and titanium ions, a hydroxyl group $(\mathrm{OH})^{-}$and the oxygen of the water molecules in the xerogel. After the thermal treatment of xerogel at a temperature of $580 \mathrm{~K}$, all water (absorbed, zeolyte type and chemically bonded) was removed from the sample, and vanadium-titaniumhydroquinone oxide bronze $\mathrm{V}_{1.67} \mathrm{Ti}_{0.33} \mathrm{O}_{5 \pm \delta} / \mathrm{HQ}$ was formed. This was confirmed by the following facts: first, we did not obtain any water traces in the bronze; second, the $\mathrm{O} 1 \mathrm{~s}$ peak of the xerogel and the bronze consists of components that correspond to $\mathrm{O}^{2-}$ ions and oxygen in the $(\mathrm{OH})^{-}$group; and finally, the $\mathrm{C} 1 s$ XPS peak analysis makes it clear that $\mathrm{C}-\mathrm{O}$ and $\mathrm{C}-\mathrm{H}$ bonding exists in the compounds investigated and these bonds are typical of the hydroquinone $\mathrm{C}_{6} \mathrm{H}_{4}(\mathrm{OH})_{2}$ molecules.

\section{References}

[1] Legendre, J.-J., Livage, J. J. Colloid. Interf. Sci. 94 (1983): 75-83.

[2] Legendre, J.-J., Aldebert, P., Baffer, N., Livage, J. J. Colloid Interf. Sci. 94 (1983): 84-89.

[3] Volkov, V. L., Zakharova, G. S., Bondarenka, V. "Xerogels of Simple and Complex Polyvanadates". Ural Branch of Russian Academy of Sciences, Yekaterinburg, 2001.

[4] Bondarenka, V. , Pašiškevicius, A., Volkov, V. L., Zakharova, G. S. Lith. J. Phys. 47 (2007): 59-62.

[5] Huguenin, F., Girotto, E. M., Torresi, R. M, Buttry, D. A. J. Electroanal. Chem. 536 (2002): $37-$ 45 .

[6] Nakato, T., Ise, T., Sugahara, Y., Kuroda, K., Kato, Ch. Mater. Res. Bull. 26 (1991): 309-315.

[7] Aldebert, P., Baffer, N., Gharbi, N., Livage, J. Mater. Res. Bull. 16 (1981): 949-955.

[8] Volkov, V. L., Zakharova, G. S., Kuznetsov, M. V., Jin, A., Zhu, Q., Chen, W. Russian J. Inorg. Chem. 51 (2006): 1339-1344.

[9] Hagenmuller, P., Galy, J., Pouchard, M., Casalot, A. Mater. Res. Bull. 1 (1966): 95-107.

[10] Evans, H. T., Hughes, J. M., Am. Mineralogist 75 (1990): 508-521.

[11] Chirayil, T. A., Zavalij, P. Y., Whittingham, M. C. Chem. Mater. 10 (1998): 2629-2640.

[12] Zhang, F., Zavalij, P. Y., Whittingham, M. C., Electrochem. Commun. 1 (1999): 564-567.

[13] Česnys, A., Tvardauskas, H., Martūnas, Z., Oginskis, A. K., Lith. J. Phys. 41 (2001): 119-123.

[14] Česnys, A., Bondarenka, V., Oginskis, A., Latyshenka, A. Lisauskas, V. J. Solid State Chem. 113 (1994): 438-440.

[15] Livage, J. Coord. Chem. Rev. 178-180 (1998): 999-1018.

[16] Livage, J., Chem. Mater. 3 (1991): 578-593.

[17] Kweon, H., Lee, K. W., Lee, E. M., Park, J., Kim, I. M., Lee, C. E., Jung, G., Gedanken, A., Koltypin, Y. Phys. Rev. B 76 (2007): 045434.

[18] Wang, X., Liu, L., Jacobson, A. J., Agew. Chem. Intern. Ed. 45 (2006): 1-5.

[19] Bonadarenka, V., Jasulaitienè, V., Sereika, R., Stirke, A. J. Sol-Gel Sci. Technol. 71 (2014): 385-390. 
[20] Bondarenka, V., Tvardauskas, H., Grebinskij, S., Senulis. M., Pašiškevičius, A., Volkov, V. Zakharova, G., Phys. Stat. Sol. C. 6 (2009): 2807-2809.

[21] Nefedov, V. I., Gati, D., Dzhurinskii, B. F., Segushin, N. P., Salyn, Y. A. Russian J. Inorg. Chem. 20 (1975): 2307-2314.

[22] Moulder, J. F., Stickle, W. F., Sobol, P. E., Bomben, K. D. Handbook of X-ray Photoelectron Spectroscopy Physical Electronics. Minnesota: Eden Praire, 1995.

[23] Bondarenka, V. Tvardauskas, H. Grebinskij, S. Mickevičius, S., Martūnas, Z., Volkov, V. Zakharova, G. Nucl. Instrum. Methods B. 178 (2001): 323-326.

[24] Bondarenka, V., Grebinskij, S., Mickevičius, S., Kačiulis, S., Pandolfi, L., Volkov, V., Zakharova, G. Lith. J. Phys. 43 (2003): 309-313 .

[25] Borgmann, D., Hums, E., Hopfengärtner, G., Wedler, G., Spitznagel, G. W., Rademacher, I. J. Electron. Spectrosc. Relat. Phenom. 63 (1993): 91-116.

[26] Bondarenka, V., Grebinskij, S., Mickevičius, S., Tvardauskas, H., Kačiulis, S., J. Alloys Compd. 382 (2004): 239-243.

[27] Bondarenka, V., Grebinskij, S., Mickevičius, S., Tvardauskas, H., Kačiulis, S., Volkov, V., Zakharova, G., Pašiškevičius, A. Lith. J. Phys. 47 (2007): 333-342.

[28] Mancia, F., Fierro, G., Ingo, M. Corrosion 45 (1989): 814-823.

[29] Yang, W. P., Costa, D., Marcus, P., J. Electrochem. Soc. 141 (1994): 2669-2676.

[30] Brox, B., Olefjord, I., Jelvestam, U., J. Electrochem. Soc. 132 (1985): 2854-2864.

[31] Bondarenka, V., Martūnas, Z., Kačiulis, S., Pandolfi, L. J. Electron. Spectrosc. Relat. Phenom. 131-132 (2003): 99-103.

[32] Bondarenka, V., Grebinskij, S., Martūnas, Z., Mickevičius, S., Tvardauskas, H. Kačiulis, S., Pandolfi, L., Volkov, V., Podvalnaia, N. Lith. J. Phys. 46 (2006): 185-190.

[33] Bondarenka, V., Kačiulis, S., Martūnas, Z., Rėza, A., Babonas, G. J., Pašiškevičius, A. Lith. J. Phys. 48 (2008): 341-348.

[34] Freyer, N., Pirug, G., Bonzel, H. P., Freyer, N., Surf. Sci. 126 (1983): 487-494.

[35] Meenan, B. J., Hewitt, J. A., Brown, N. M. D., Surf. Interface Anal. 18 (1992): 187-198. 